\title{
O LUGAR DO COTIDIANO NAS ESCOLAS RURAIS
}

Darieli Daltrozo Ilha

Simone da Silva Ribeiro

Dileno Dustan Lucas de Souza ${ }^{(*)}$

$$
\begin{array}{r}
\text { Uso a palavra para compor meus silêncios. } \\
\text { Não gosto das palavras } \\
\text { fatigadas de informar. } \\
\text { Dou mais respeito } \\
\text { às que vivem de barriga no chão } \\
\text { tipo água, pedra, sapo. } \\
\text { Entendo bem o sotaque das águas } \\
\text { Dou respeito às coisas desimportantes } \\
\text { e aos seres desimportantes. } \\
\text { Prezo insetos mais que avióes. } \\
\text { Prezo a velocidade } \\
\text { das tartarugas mais que a dos mísseis. (...) } \\
\text { Meu quintal é maior do que o mundo. } \\
\text { (Manoel de Barros) }
\end{array}
$$

Ao nos deleitarmos com as palavras de Manoel de Barros, poeta que exalta a natureza e a vida no campo com tanta maestria, também somos incitados a ver o mundo a partir de outras lógicas. Poderíamos dizer que entender o sotaque das águas e prezar pela velocidade das tartarugas foge à racionalidade do pensamento moderno que norteia o nosso cotidiano e a nossa escola. No entanto, queremos destacar com esse texto lugares, cotidianos e sujeitos que traduzem essa fuga, voltando o olhar para comunidades rurais e suas escolas.

As inspirações que deram origem a esse texto partiram de uma pesquisa de mestrado realizada em escolas rurais de Juiz de Fora, município da Zona da Mata de Minas Gerais, onde pessoas que vivem nas comunidades rurais de Monte Verde e Torreões contaram as suas trajetórias de vida e suas experiências vinculadas à história de suas escolas. Destacaremos aqui a história de Vanda $^{1}$, que apresenta as suas vivências da época da infância entrelaçando os saberes e fazeres em meio a sua família com a rotina de atividades trabalhadas na escola. Partindo dessa contextualização inicial, temos como objetivo refletir sobre o lugar do cotidiano e a construção do conhecimento dentro e fora da escola rural, sustentado pelo ideário de Paulo Freire e Michel de Certeau sobre os sujeitos e seus cotidianos. Também nos propomos a analisar práticas avaliativas focadas na alfabetização, empreendidas por escolas rurais nas décadas de 1980/1990, período de grande

\footnotetext{
${ }^{(*)}$ Darieli Daltrozo Ilha. Mestre em Educação, Professora dos anos iniciais do Ensino Fundamental do Colégio de Aplicação João XXIII da Universidade Federal de Juiz de Fora

Simone da Silva Ribeiro. Doutora em Educação, professora EBTT do Colégio de Aplicação João XXIII da Universidade Federal de Juiz de Fora

Dileno Dustan L. Souza. Pós-doutor em Educação, professor associado da Faculdade de Educação da Universidade Federal de Juiz de Fora.

${ }^{l}$ A entrevistada autorizou a divulgação do seu nome para a referida pesquisa e aos seus resultados.
} 
migração campo/cidade ocorrida no município pesquisado. Além da fala da entrevistada, teremos como material de análise os exames de leitura realizados na época.

A narrativa de Vanda deu sentido à afirmação de que o quintal é maior que o mundo. Será que é possível construir conhecimentos em espaços alheios à escola? O que uma agricultora tem a nos ensinar? Como a avaliação está inserida no contexto das escolas rurais? Tais inquietações que nos motivaram, e entendemos que também serão motivadoras dos leitores, serão contempladas ao longo deste texto que se estrutura em torno das seções que versam sobre os sujeitos e seus cotidianos, os conhecimentos dos agricultores expresso na narrativa de Vanda e o lugar da avaliação nas escolas rurais.

\section{OS SUJEITOS DO COTIDIANO}

Os estereótipos socialmente construídos em torno do camponês o concebem como um sujeito rudimentar, atrasado e alheio à civilização. As lentes modernas e eurocêntricas que definiram tal estereótipo imprimiram ao camponês uma imagem negativa de muitas ausências. No entanto, queremos aqui "mudar as lentes" e lançar o olhar sobre os agricultores, trabalhadores e moradores de comunidades rurais a partir de outra lógica, considerando-os como sujeitos que constroem cotidianamente suas existências criando e recriando diferentes artes de fazer a vida acontecer. Michel de Certeau e Paulo Freire irão nos oferecer novas lentes, pois seus estudos nos instrumentalizam no sentido de conferir às pessoas um papel de protagonismo desempenhado nos seus espaços sociais.

Essa leitura é necessária porque a sociedade tende a tolher e menosprezar a capacidade criadora, os conhecimentos e saberes construídos por agricultores, trabalhadores braçais, pessoas simples que povoam as vilas, comunidades rurais ou subúrbios urbanos, ideia essa que perpassa milênios e vem desde a Grécia antiga, que separava os cidadãos dos demais em função do trabalho e do gênero. Será que são apenas vítimas e meros reprodutores de um sistema dominante de cultura, valores, trabalho? A vida e o cotidiano destas pessoas podem se constituir numa categoria de análise? E o que é o cotidiano para que nos interessemos por ele?

O cotidiano é aquilo que nos prende intimamente, a partir do interior. É uma história a meio-caminho de nós mesmos, quase em retirada, às vezes velada. Não se deve esquecer esse "mundo memória", segundo a expressão de Péguy. É um mundo que amamos profundamente, memória olfativa, memória dos lugares da infância, memória do corpo, dos gestos da infância, dos prazeres. (CERTEAU, 2011, p. 31). 
Um mundo-memória que revela as diferentes faces da vida cotidiana e as formas com que pessoas simples para as quais a sociedade, a História ou o espaço acadêmico relegaram um lugar marginal. O que sempre ficou oculto tanto nos discursos, como no campo de pesquisas acadêmicas foi esse rico cenário que envolve a vida de pessoas comuns em todas as suas faces: o que pensam, o que sentem, como produzem conhecimento, como trabalham, que lógicas norteiam as suas vidas e de suas comunidades? O ponto forte dessa abordagem é o lugar em que Certeau coloca esses sujeitos. Nas relações de poder existentes na sociedade, a primeira impressão é que eles são meros expectadores de uma cultura dominante e massificadora. Esse fato é real até certo ponto, pois o autor argumenta que esses diferentes grupos têm maneiras próprias de "consumir" essa cultura, o que não ocorre da forma pacífica como parece. Consciente ou inconscientemente esses sujeitos criam e recriam formas de resistência e de subversão expressas nas suas astúcias, capacidades criativas e engenhosidades ao trilharem seus próprios caminhos, transformando ou se distanciando do que lhes foi imposto pelos dominadores.

O exemplo dado por Certeau (1994, p. 39-40), nesse sentido, foram as relações entre etnias indígenas e os colonizadores espanhóis:

[...] muitas vezes esses indígenas faziam das ações rituais, representações ou leis que lhes eram impostas outra coisa que não aquela que o conquistador julgava obter por elas. Os indígenas as subvertiam [...]. supõe que à maneira dos povos indígenas os usuários façam uma bricolagem com e na economia cultural dominante, usando inúmeras e infinitesimais metamorfoses da lei, segundo seus interesses próprios e suas próprias regras.

Ao fazer essa leitura, é possível lembrar a história dos negros no Brasil que, ao terem imposta a religião dos colonizadores, criaram a alternativa de trocar apenas os nomes das divindades que cultuavam pelos nomes dos santos católicos, não deixando assim de prestar culto aos seus deuses. Fazendo referência às práticas da comunidade rural onde nasci, destaco a rede de solidariedade que existia entre os vizinhos. Em meio às carências, a força motriz criativa das pessoas levava a comunidade a desenvolver técnicas de armazenamento e troca de alimentos quando não havia refrigerador; a criação de receitas popularmente chamadas de "chapueiradas", que eram misturas de plantas medicinais destinadas à cura de vários tipos de doenças; a construção de artesanatos a partir de elementos comuns na região, como a palha de milho, o trigo e a linhaça; o uso do rádio como a principal forma de comunicação entre as famílias e a utilização de rodas d'água para produção de farinha de trigo e milho nos moinhos, ao mesmo tempo em que produziam energia elétrica. 
No âmbito da educação também encontramos tais iniciativas. Ribeiro (2016a) apresenta a sua pesquisa que dá visibilidade às táticas de professoras de escolas rurais que estão construindo a proposta de educação do campo na sua escola. Suas histórias de vida, suas práticas cotidianas em sala de aula criativas e inseridas na realidade de seus alunos demonstram suas astúcias e engenhosidades ao lidar com uma instituição fincada nos pilares da modernidade, mas inserida em um espaço criado e recriado por elas, por seus alunos e pela comunidade rural onde se localiza a escola.

Nesses exemplos ficam evidentes formas de resistência, de artimanhas e burlas colocadas em ação através de um jogo de táticas que fazem oposição aos elementos determinantes da sociedade impostos por grupos e/ou instituições majoritários através de suas estratégias como ação de intimidação e firmação dos fortes sobre os fracos, o que é um marco da modernidade. Nesse sentido, a tática é considerada "movimento dentro do campo de visão do inimigo, [...] é a arte do fraco" (CERTEAU, 1994, p. 100, 101) que o instrumentaliza a lidar com as diferentes situações do cotidiano burlando o poder estabelecido ao estabelecer seus mecanismos próprios de manutenção da vida.

Partindo da ótica de Certeau, o cotidiano é apresentado por uma nova perspectiva e o sujeito que o dá sentido através de suas maneiras de fazer, muitas vezes anônimas, também toma um lugar diferente. O "sujeito ordinário" é...

Herói comum. Personagem disseminada. Caminhante inumerável. [...] Este herói anônimo vem de muito longe. É o murmúrio das sociedades. De todo o tempo, anterior aos textos. Nem os espera. Zomba deles. Mas, nas representações escritas, vai progredindo. Pouco a pouco ocupa o centro de nossas cenas científicas. Os projetores abandonaram os atores donos de nomes próprios e de brasões sociais para voltar-se para o coro dos figurantes amontoados dos lados, e depois fixar-se enfim na multidão do público (p. 57).

Este sujeito anônimo passa a ser visto por historiadores e pesquisadores das mais diversas áreas do conhecimento, o que lhes têm conferido uma visibilidade nunca antes possível além de uma nova perspectiva que contempla a construção de sentidos próprios que vão além das ciências. São apresentadas novas lógicas que desafiam a razão moderna e seus sentidos socialmente definidos. No entanto, houve pesquisadores que foram além das análises descritivas, as quais foram importantes, mas que, a meu ver, deixaram de lado um importante tempero: o papel transformador desses sujeitos. Paulo Freire usa esse tempero e coloca a educação como uma ferramenta 
fundamental de conscientização para que esses sujeitos compreendam-se com tal. Assim, o esforço do autor que

[...] se fixou na busca desse homem-sujeito que, necessariamente, implicaria em uma sociedade também sujeito. Sempre lhe pareceu, dentro das condições históricas de sua sociedade, inadiável e indispensável uma ampla conscientização das massas brasileiras, através de uma educação que as colocasse numa postura de autorreflexão e de reflexão sobre seu tempo e seu espaço. [...] Autorreflexão que as levará ao aprofundamento consequente de sua tomada de consciência e de que resultará sua inserção na História, não mais como espectadores, mas como figurantes e autoras (FREIRE, 2002, p. 44).

Os homens-sujeito se contrapõem aos homens-objeto. Enquanto estes possuem uma consciência povoada pela sombra invasora dos opressores, adotando um eu que não lhes pertence, domesticado e acomodado; os homens-sujeito são historicamente situados, atuantes em interação com os demais através do diálogo e posicionam-se criticamente diante dos desafios do seu tempo, não apenas prendendo-se ao mundo das ideias, mas agindo com o objetivo da transformação da realidade. O processo para tornar-se envolve a noção de "inacabamento ou inconclusão," (FREIRE, 1989, p. 27) compreendida como a força motriz da ação do sujeito na busca constante e contínua do conhecimento, o que também lhe confere o ímpeto de criar.

Nesse sentido é que Freire reconhece outro atributo do sujeito: a cognoscibilidade, que, muito além de um adjetivo, é ressignificada ao ser incorporada ao conceito de sujeito cognoscente, que não é apenas o cientista, o pesquisador da academia ou o herói burguês, mas sim uma capacidade inerente à raça humana. Em suma, a consciência de quem ele é no mundo e de que pode vir a ser mais num crescente processo de humanização o leva a pensar, refletir, agir para mudar, transformar, inventar. Tudo isso é possível através de uma relação dialógica e problematizadora que rechaça a transmissão de conhecimento polarizada e, ao contrário, caracteriza a busca constante, a ação curiosa, o inventar e o reinventar. A concepção humanizadora do autor o leva a afirmar que esses processos concretos de aprendizagem que culminam na produção do conhecimento não são possíveis fora das relações, ações e significações dos sujeitos cognoscentes.

Outra categoria da obra de Freire pertinente a nossa discussão sobre o sujeito e a produção do conhecimento é a curiosidade. Ele a apresenta como curiosidade epistemológica porque "é enquanto epistemologicamente curiosos que conhecemos, no sentido de que produzimos o conhecimento e não apenas mecanicamente o armazenamos na memória” (FREIRE, 1994, p. 148). Essa característica curiosa peculiar aos sujeitos cognoscentes os instrumentaliza a contrapor certezas e ir à busca de novas descobertas a partir de seus cotidianos, seus saberes, sua cultura e 
suas necessidades reais, potencializadas por uma educação libertadora e pela práxis, ou seja, a açãoreflexão-ação que transforma o mundo. Nessa perspectiva, o ato de conhecer se firma numa concepção crítica.

Freire também volta o olhar para o cotidiano e parte dele para construir sua teoria epistemológica e política. A leitura de mundo que perpassa suas obras nos desafia a conhecer e agir sobre a realidade que nos cerca. A esse respeito, Ana Maria Freire apresenta uma análise muito esclarecedora:

O cotidiano em Paulo Freire foi algo além dos conceitos proclamados nos dicionários, como aquilo que se faz ou se sucede todos os dias, o que acontece ou se pratica habitualmente, concepções que traduzem, por sua vez, o que vem do senso comum socializado por nós todos: a repetição de algo rotineiramente, mecanicistamente. $\mathrm{O}$ cotidiano na leitura de mundo de Paulo supera esse entendimento. Resgata a natureza substantivamente rica e plena de vida que os atos, os gestos e as palavras, mesmo que simples de todos os dias e de todas as horas, restauram da dignidade do mais autenticamente humano que temos em nós, mulheres e homens, na vivência da cotidianidade. O cotidiano é humano. (FREIRE, 2006, p. 334).

Os círculos de cultura, as campanhas de alfabetização, os movimentos de cultura popular são exemplos práticos dessa visão. Os temas geradores que embasavam cada atividade partiam sempre de questões reais que os grupos envolvidos estavam vivenciando a nível local ou nacional. Prática presente inclusive no seu Método de Alfabetização, que trabalhava as palavras, escolhidas pelos grupos e advindas de seus universos vocabulares. Num primeiro momento, tornavam-se tema para reflexão, para depois serem decodificadas no processo de construção da língua escrita (FREIRE, 2002).

Vemos assim as expressões de uma educação problematizadora que contrapõem a concepção de educação bancária, onde o conhecimento é colocado nos alunos como depósitos numa relação unilateral professor - aluno (FREIRE, 1989). O autor nos auxilia na análise do sujeito e seu cotidiano e vai além porque traz para a discussão a dimensão educacional nos apontando caminhos para uma prática pedagógica diferenciada que justamente se embase nessas categorias.

Embora divergentes em alguns aspectos, o fato é que Freire e Certeau nos ajudam a repensar nossas áreas de pesquisa e principalmente, ampliam nossa visão de mundo ao nos fornecer lentes de análise que nos permitem vislumbrar os "heróis obscuros de que somos devedores e aos quais nos assemelhamos" (CERTEAU, 2011, p. 32). 


\section{OS SABERES E FAZERES DOS POVOS DO CAMPO E SUAS INTERFACES COM A ESCOLA}

Heróis e heroínas anônimos constroem, criam, inventam, confundem-se com o lugar onde vivem marcando identidades próprias individuais e coletivas. Nesse sentido, daremos voz a uma mulher que sempre morou em uma comunidade rural e teve uma vida marcada pelo amor à escola e o desejo de estar nela. Um desejo comum a grande maioria dos moradores do campo, mas que nem sempre pode ser realizado porque as escolas disponíveis em suas comunidades não disponibilizam todas as etapas de ensino, obrigando as famílias a tomarem uma dura decisão com suas crianças e jovens: parar de estudar ou continuar a escolarização na cidade, o que muitas vezes se configura como um caminho sem volta. A opção de Vanda e sua família foi parar de estudar pela falta de continuidade da antiga $4^{\mathrm{a}}$ série, que era oferecida na escola de onde morava, aliada à necessidade de trabalhar para ajudar na renda da família.

Vanda foi uma das ex-alunas de escolas rurais que tivemos o privilégio de conhecer ao longo da nossa jornada investigativa. Chegamos até ela através de uma compilação de trabalhos encontrados na Secretaria Municipal de Educação, onde ela ilustrou uma história conhecida da comunidade onde mora e contada diversas vezes nas rodas de conversa na sua casa. Mas a contribuição de Vanda vai muito além do desenho de uma criança curiosa e desejosa de aprender. Essa história é apenas uma das muitas que ela e seus irmãos ouviram de seu pai e configura uma memória viva de momentos marcantes da sua infância, onde a aprendizagem pela observação e participação da rotina de trabalho da família e das rodas de história nos momentos de descanso foram experiências de grande significado tanto para sua trajetória de vida quanto para nossa reflexão que queremos aqui empreender.

Hoje vem à tona a lembrança de um pouco de tudo: das cantigas, das histórias, de um pouco de tudo de plantação, de saber quando vem a chuva ou não... Uma criança hoje olha e fala: "mas como pode? De que jeito? Como é que você sabe?" Então, meu avô me ensinou, meu pai me ensinou (FERREIRA, 2017).

Será que aprendemos os saberes necessários para a vida somente dentro do espaço escolar? $\mathrm{O}$ que tem a nos ensinar um homem analfabeto que sempre viveu na roça? Um cidadão urbano imerso na cultura letrada e acadêmica responderia que muito pouco, talvez a paciência, a humildade e a simplicidade. Mas para quem teve essa vivência, a resposta assume outra proporção:

[...] Meu avô era muito rico em histórias. Ele sabia ver chuva, os sinais da chuva, sabe? E ele passava tudo para a gente e eu o acompanhava muito, eu me desvinculava do grupo dos meus irmãos e o seguia porque eu achava muito bonito vê-lo cuidando do cafezal. Quando ele percebia que eu estava perto, ele não zangava, me chamava 
para perto e dizia "você tem que fazer assim para a planta sair de tal jeito". [...] Não sei de onde vinha tanta sabedoria (FERREIRA, 2017).

Vanda descreve como seu avô organizava a sua rotina de trabalho, os produtos que produzia e as estratégias para estocar os alimentos que ele colhia. A diversidade de plantas que ele cultivava com carinho expressa uma lógica cara aos dias de hoje: "a terra não é só para sobreviver, tem que cuidar dela também" (FERREIRA, 2017). Tudo tinha um porquê e a neta curiosa e ansiosa em aprender observava e escutava todos os ensinos do avô. Essa conduta de criança curiosa possibilitou a construção de aprendizagens que tiveram significado, e por isso foram tão marcantes na sua vida. Freire (1996, p. 95) denota que "a construção ou a produção do conhecimento do objeto implica o exercício da curiosidade".

Da mesma forma, descreve as lembranças de criança ao vivenciar a rotina de trabalho do pai que era assalariado e agricultor ao mesmo tempo, pois a renda proveniente da roça não era suficiente para garantir o sustento da família. Ao chegar do trabalho assalariado às 4 horas da tarde, os filhos o acompanhavam à roça em meio a tarefas e brincadeiras. Mas o momento mais esperado do dia era a roda de histórias contadas no tapete de couro de boi confeccionado pelo pai. Era o lugar mais especial da casa e toda a família participava deste momento de conversa e histórias. Foi nesse espaço que Vanda e seus irmãos ouviram histórias como "A luz misteriosa”, "O poço de água doce", "O cavaleiro da meia-noite”, "Zé Pequeno" e causos de assombração. Vanda expressa sua admiração pela sabedoria de seu pai: "Era um livro... E uma pessoa que assinava só o nome”! São lembranças de histórias e de momentos privilegiados de aprendizagens que envolviam lições de vida, cultivo da terra e observação dos sinais da natureza.

A suposição de que o único local para adquirir o conhecimento válido para a vida passa exclusivamente pela escola, de certa maneira, causa um sentimento de surpresa em Vanda. Como poderia um homem iletrado ter tamanha sabedoria e articular estratégias para facilitar o trabalho cotidiano e possuir tantos saberes e histórias para compartilhar com os filhos? Damasceno (1993) tece uma crítica nesse sentido, alegando que os trabalhadores do campo têm sua condição de sujeitos pensantes e produtores de conhecimento e cultura negados. É um estereótipo social muito arraigado e que precisa ser desmistificado.

As narrativas gravadas na memória carregam consigo muitos significados, inclusive o de que essas "artes de dizer", como caracteriza Certeau (1994, p. 85), carregam os discursos do povo, suas fugas e astúcias ao assumirem-se como protagonistas de seus contos, lendas e histórias:

Uma formalidade das práticas cotidianas vem à tona nessas histórias, que invertem frequentemente as relações de força. [...] Essas histórias "maravilhosas" oferecem a 
seu público (ao bom entendedor, um cumprimento) um possível de táticas disponíveis no futuro. [...] A retórica e as práticas cotidianas são igualmente definíveis como manipulações internas a um sistema - o da língua ou ao de uma ordem estabelecida. [...] Inscrevem na língua ordinária as astúcias, os deslocamentos, elipses, etc. que a razão científica eliminou dos discursos operatórios para construir sentidos próprios (CERTEAU, 1994, p. 85).

A escola, assumindo a lógica da razão científica, desconsiderou essa realidade. Mesmo reconhecendo o protagonismo de seus pais e avós na produção de conhecimentos e lógicas de trabalho no campo, Vanda se apropria do discurso da escola desvinculada da sua realidade ao destacar a ruptura de suas vivências ao começar o processo de escolarização: “[...] Aí depois veio à época da escola, a gente tinha que estudar e então fui para a escola de Monte Verde" (FERREIRA, 2017). Parece que seus processos de aprendizagem são diferentes na vivência com seu avô e no cotidiano escolar. Agora ela precisava adequar-se a novos tempos, à rigidez de um comportamento perfeito e uma disciplina severa, à novos conteúdos, à seriedade da sala de aula. E tais práticas juntam-se a tantas outras que caracterizam a instituição escola e suas rotinas. No entanto, essa não é uma peculiaridade de uma escola isolada, mas é sim uma construção histórica que remonta o início da institucionalização do ensino, uma marca da modernidade. É nesse sentido que argumenta Dussel e Caruso (2003) ao qualificar a escola que conhecemos hoje como uma invenção da modernidade para produzir o cidadão moderno, trabalhador da indústria, habitante da cidade, carregado de obrigações, onde o ensino na sala de aula se constitui como uma estrutura de poder particular.

Sendo assim, que lugar ocupa o agricultor na escola destinada a ele? Até pouco tempo atrás, e ainda em muitas regiões do Brasil, a escola rural teve a mesma característica:

Temos uma larga história que sempre defendeu que os saberes que a escola rural deve transmitir devem ser poucos e úteis para mexer com a enxada, ordenhar a vaca, plantar, colher, levar para a feira... Aprender apenas os conhecimentos necessários para sobreviver e até para modernizar um pouco a produção, introduzir novas tecnologias, sementes, adubos, etc. Essa visão utilitarista sempre justificou a escola rural pobre, os conteúdos primaríssimos, a escolinha das primeiras letras (ARROYO, 1999, p. 17).

A escola rural também foi pensada e moldada dentro da racionalidade moderna, atendendo a diferentes interesses ao longo do seu percurso, menos os dos sujeitos do campo. Ainda encontramos comumente em comunidades mais isoladas essa escola tipificada por Arroyo: precária e utilitarista. Em outros lugares, normalmente em locais mais próximos das cidades, há um tipo de escola mais 
estruturada fisicamente e com recursos financeiros e pedagógicos tipicamente urbana situada no espaço rural. É exatamente o caso das escolas das comunidades rurais pesquisadas. Entretanto, em todos esses contextos, o ponto comum é o descrédito pela vida no campo e, com isso, a partida dos jovens para buscar uma oportunidade de trabalho na cidade ou em grandes empresas rurais. Perdem sua identidade e sua terra em prol de uma dita "civilidade". Nesse caso, Ribeiro (2016b, p. 28) denuncia: “A escola rural [...] oferece uma educação voltada à vida na cidade, mantendo o histórico preconceito em relação ao trabalho e o mundo rural e ignorando o que, através dele e nele, se produz/reproduz em termos de vida, alimentos, saberes e cultura".

Vemos, portanto, na escola rural pensada para os povos do campo, diversas marcas da modernidade como demonstrado por Quijano (2005). A superioridade de um povo, de uma cultura e de seus saberes sobre outros povos, classificando estes como inferiores é uma clássica assertiva da modernidade. E fica evidente que o modelo de escola que temos segue esses mesmos princípios. A escola ignora os saberes dos povos do campo, além de depreciar sua vida e cultura porque no imaginário social o que se relaciona ao campo remete a um personagem ignorante, sujo e avesso à civilização, caracterizado no Jeca Tatu e que carrega em seu bornal conceitual as matrizes da modernidade, com suas epistemologias eurocêntricas. Essa caricatura dos povos do campo perpassa gerações.

Outra marca da modernidade, segundo Boff (1999), é a falta de cuidado. Pilares básicos da modernidade como o individualismo, a exploração e o domínio indiscriminado da natureza em vista do desenvolvimento e do progresso das nações, levaram o ocidente a um comportamento endêmico de falta de cuidado à vida em todas as suas dimensões. Por isso, a doce memória de Vanda, ao falar sobre o amor do seu avô pela terra, a faz refletir sobre os valores do ser humano com seu semelhante e seu ambiente. "Cuidar é mais que um ato; é uma atitude. Portanto, abrange mais que um momento de atenção, de zelo e de desvelo. Representa uma atitude de ocupação, preocupação, de responsabilização e de envolvimento afetivo com o outro" (BOFF, 1999, p. 12).

O cuidado, o amor pela terra e pela presença do outro, a solidariedade, a aprendizagem pela prática e pela observação tendo a família e a comunidade como o núcleo ensinante, o gosto pelas histórias e pela "boniteza das palavras", como diria Freire, são elementos valorizados pela Vanda, e, segundo sua análise, são conceitos que devem andar lado a lado e em harmonia com as tecnologias e outros avanços científicos da modernidade. Tudo isso deve estar presente na escola, ser conteúdo de ensino. Compartilhamos desta mesma ideia. A prática de classificar e hierarquizar povos, conhecimentos, saberes e culturas, foi um marco da modernidade e do tipo de escola "inventada" a partir desse contexto. 
Damasceno (1993) caracteriza essa gama de elementos produzidos, organizados e efetivados a partir das necessidades e aprendizagens do cotidiano dos grupos camponeses como um "saber social" decorrente da experiência acumulada. A autora chama a atenção para o fato de que há uma tradição de negação desses saberes, ao mesmo tempo em que aponta para a necessidade de que esse saber social se articule com o saber científico como uma tessitura. Será que podemos (re) pensar a escola aliando os conhecimentos elencados pela Vanda às conquistas da humanidade na sua trajetória evolutiva?

\section{O LUGAR DA AVALIAÇÃO NAS ESCOLAS RURAIS: O EXEMPLO DOS TESTES DE LEITURA}

A separação entre os saberes e vivências dos alunos que chegam às escolas rurais e os saberes nelas transmitidos e trabalhados foi uma realidade vivida por Vanda, e podemos afirmar que não se trata de um caso isolado, mas de gerações de crianças que estudaram ou estudam em escolas rurais. Isso se reflete diretamente no processo de aprendizagem, aliado a problemas como a inadequação curricular, a multirrepetência, principalmente no primeiro ano escolar, a grande rotatividade de professores, os problemas no transporte e a ausência de formação específica para os professores trabalhares nas escolas rurais (RIBEIRO, 2016b).

Em meio a esse contexto, insere-se a concepção de avaliação presente não só na década de 1990, época em que Vanda se alfabetizou, mas ainda hoje configura uma realidade em diversas escolas, sejam urbanas ou rurais, "uma concepção de escola seletiva na qual a avaliação tenha como objetivo medir resultados finais em detrimento da aprendizagem” (CRUZ, 2012, p. 19), ou seja, uma medida do desempenho dos alunos.

Queremos trazer para reflexão o teste de leitura, prática avaliativa vivida por Vanda no seu primeiro ano de alfabetização e que consistia num teste de leitura de palavras e de textos com interpretação, seguido de produção textual aplicado pelas supervisoras da Secretaria Municipal de Educação, que se deslocavam às escolas rurais em períodos pré-estabelecidos, após o cumprimento de conteúdos de ensino determinados pela Secretaria. Quando as supervisoras chegavam à escola, havia casos de crianças que não conseguiam ler uma palavra sequer. Então elas voltavam outro dia para repetir o teste.

Ao lembrar-se dos testes de leitura, Vanda destacou que este era o grande pavor dos alunos. Quem era bem sucedido, segundo ela, considerava tal feito como "tirar a identidade pela primeira vez". 
Tinha que ir. Tinha que estar certo e tinha que passar porque era obrigação. A gente não podia ficar preso por muito tempo não! Na hora de fazer o teste, às vezes o texto estava na ponta da língua, mas... o nervosismo! [...] As professoras iam passando redação para fazer, era composição na época. Às vezes têm umas tarefas e esquecia a composição. Fazia de última hora e aí... Zero e castigo! O castigo era ficar sem recreio uns minutos. Nada severo, mas tinha que respeitar (FERREIRA, 2017).

As fichas que continham os resultados desses testes demonstravam uma média gritante de $50 \%$ de repetência ao final do primeiro ano. Era comum, segundo o registro de Vanda, encontrar nessas turmas crianças de 13 e até 14 anos, multirrepetentes. Relatórios do período 1980-1990² manuscritos pelas professoras mostrando as possíveis causas do baixo rendimento e evasão dos alunos, apontando várias questões que dificultavam a vida escolar das crianças. As que se sobressaíram foram: dificuldades de aprendizagem, infrequência, cansaço gerado pelo trabalho, trabalho em casa e fora de casa, problemas familiares como alcoolismo, desnutrição, problemas de saúde, difícil acesso à escola e algum tipo de deficiência. Tais questões denotam carências e ausências do Estado para com o campo, pois se considera a falta de atendimento adequado à saúde e de infraestrutura básica nas localidades rurais, bem como as difíceis condições de trabalho a que muitos agricultores eram submetidos. Por outro lado, os relatórios de visitas das supervisoras e avaliações das professoras também encontrados nos arquivos denunciavam a falta de material escolar, de merenda, de utensílios para cozinhar, refrigeradores, e até mesmo a falta de energia elétrica e água (algumas escolas não tinham ligação elétrica). Há inclusive sugestões de professores que solicitavam a reconstrução de prédios em que funcionavam as escolas tendo em vista as péssimas condições de conservação.

Em meio a esse cenário desfavorável, cada criança deveria chegar ao final do primeiro ano, lendo e escrevendo de forma alfabética, o que seria demonstrado através do teste de leitura. Como consequência, o resultado determinava quem iria avançar para o ano seguinte. É claro que este seria um objetivo condizente ao que se espera de uma turma de primeiro ano, mas uma avaliação centrada no aluno e que enfatizava seus fracassos como um problema individual, desconsiderava a luta diária que cada criança enfrentava para estar sentada em uma sala de aula precária diante de seu professor. O fracasso gerou a evasão ou a constatação de que a escola rural era ineficaz, e por isso era necessário buscar uma escola na cidade. A migração em massa do campo para a cidade nas décadas de 1980 a 1990 ocorridas no município decorreram principalmente de questões ligadas a escola e ao trabalho, que foi ficando cada vez mais escasso.

\footnotetext{
${ }^{2}$ Material não publicado. Fonte: arquivo do setor de Memória da Secretaria Municipal de Educação.
} 
Uma vez apresentado o contexto que envolve os alunos das escolas rurais, a avaliação parece ser apenas uma das muitas faces dos grandes desafios enfrentados pelos alunos das escolas rurais. A questão central reside no lugar que os sujeitos do campo ocupam quando se trata de produção de conhecimentos, como já referido através das reflexões de autores como Certeau e Freire. Onde estão seus saberes? Podemos afirmar, a partir das reflexões apresentadas, que os quintais, as lavouras, as hortas, os espaços coletivos das comunidades, o imaginário dos povos do campo repletos de histórias e conhecimentos construídos e passados de uma geração à outra são fontes curriculares. Isso significa que as escolas rurais têm ao seu redor a mais fecunda fonte inspiradora, a matéria-prima para trabalhar os diversos conceitos científicos propostos nas bases nacionais curriculares.

\section{CONSIDERAÇÕES FINAIS}

Podemos dizer que queremos com este texto dar visibilidade aos sujeitos do campo, suas lógicas e seus conhecimentos. Uma escola que pensa seu currículo e suas práticas pedagógicas a partir desse princípio confere aos seus alunos e aos seus lugares de existência uma posição de protagonismo na afirmação de suas identidades e de seus fazeres no campo. Partindo do princípio de Hadji (2001), essa escola pensaria uma avaliação numa perspectiva multidimensional, focada no processo de aprendizagem e em todos os elementos que o envolvem, direta ou indiretamente, seja a sala de aula, a instituição escolar e o que está além de seus muros. A perspectiva apresentada se insere numa visão formativa e emancipadora do aluno, levando em conta seu ponto de partida, ou seja, seus conhecimentos construídos, o processo de construção de conhecimentos novos pensados e trabalhados tendo por base os objetivos de ensino, e os avanços alcançados ao final de cada etapa.

Em se tratando especificamente da alfabetização, trazemos a referência do material de estudo do Pacto Nacional pela Alfabetização na Idade Certa, programa nacional de formação de professores alfabetizadores iniciado em 2012, concebendo que a avaliação tem como objetivo:

Regular e adaptar a prática pedagógica às necessidades dos alunos, considerando nesse processo avaliativo o professor, o aluno, a escola e a família. Nesse sentido, uma proposta avaliativa na alfabetização precisa ponderar a perspectiva que não exclui a criança, mas que a agrega ao processo de construção do conhecimento, considerando todas as variáveis possíveis (CRUZ, 2012, p. 19).

Entendemos que a avaliação está presente desde o início das práticas de aprendizagem, a partir do momento em que os professores a utilizam para identificar os conhecimentos prévios dos alunos, para planejar atividades adequadas que atendam às necessidades individuais e coletivas da 
turma, verificar o que foi aprendido e como pode ser retomado, analisar as próprias estratégias de ensino utilizadas e os progressos alcançados pelos alunos.

Quanto ao cotidiano do campo presente na escola e, consequentemente, na sua concepção avaliativa, destacamos o trabalho realizado nas Escolas Família Agrícola que, segundo Ribeiro (2010), organizam suas atividades pedagógicas seguindo a base nacional curricular, aliando tais conhecimentos às necessidades e práticas cotidianas de trabalho no campo, instrumentalizando os alunos a continuarem em suas comunidades, produzindo e diversificando a produção através das tecnologias desenvolvidas dentro da perspectiva agroecológica, ou seja, compreendendo que é possível produzir alimentos mais saudáveis sem agredir o meio ambiente.

Queremos enfatizar, a partir dessas perspectivas, que existem outras lógicas de construção de conhecimento, de fazer escola, de produzir alimentos, de se constituir como sujeitos do campo. Precisamos nos despir de certezas que sempre regeram nossas vidas e abrir-se ao som do sotaque das águas e a riqueza de um quintal que se tornou maior que um mundo inteiro de constâncias. 


\section{REFERÊNCIAS}

ARROYO, Miguel Gonzalez. A educação básica e o movimento social do campo. In: ARROYO, M.G.; FERNANDES, B.M. Por uma educação básica do campo. Brasília, DF: Editora Universidade de Brasília, 1999. p. 8-26.

BARROS, Manoel de Barros. O apanhador de desperdícios. Disponível em: <https://www.revistabula.com/2680-os10-melhores-poemas-de-manoel-de-barros/>. Acesso em 13 jul. 2018.

BOFF, Leonardo. Saber cuidar: ética do humano - compaixão pela terra. Petrópolis, RJ: Vozes, 1999.

CERTEAU, Michel de. A invenção do cotidiano: artes de fazer. Petrópolis, RJ: Vozes, 1994.

. A invenção do cotidiano 2: morar, cozinhar. 10 ed. Petrópolis, RJ: Vozes, 2011.

CRUZ, Magna C. Silva. Avaliação no ciclo de alfabetização: o monitoramento do processo de ensino e de aprendizagem das crianças. In: BRASIL. Secretaria de Educação Básica. Pacto Nacional pela alfabetização na idade certa: currículo no ciclo de alfabetização: consolidação e monitoramento do processo de ensino e de aprendizagem. ano 2, Unidade 1. Brasília: MEC, SEB, 2012. p. 19-26.

DAMASCENO, Maria Nobre. A construção do saber social pelo camponês na sua prática produtiva e política. In: THERRIEN, J.; DAMASCENO, M. N. Educação e escola no campo. Campinas, SP: Papirus, 1993. p. 53-73.

DUSSEL, Inés; CARUSO, Marcelo. A invenção da sala de aula: uma genealogia das formas de ensinar. São Paulo: Moderna, 2003.

FERREIRA, Vanda Maria da Silva. Entrevista de história oral [11, out., 2017].

FREIRE, Ana Maria Araújo. Paulo Freire: uma história de vida. Indaiatuba, SP: Villa das Letras, 2006.

FREIRE, Paulo. Educação como prática da liberdade. Rio de Janeiro: Paz e Terra: 2002.

Educação e mudança. 15. ed. Rio de Janeiro: Paz e Terra, 1989.

Cartas à Cristina. Rio de Janeiro: Paz e Terra, 1994.

. Pedagogia da Autonomia: saberes necessários à prática educativa. São Paulo: Paz e Terra, 1996.

HADJI, Charles. Avaliação desmistificada. Porto Alegre: Artes Médicas, 2001.

QUIJANO, Aníbal. Colonialidade do poder, eurocentrismo e América Latina. In: LANDER, Edgardo. A colonialidade do saber: eurocentrismo e Ciências Sociais. Buenos Aires: CLACSO, 2005. p. 227-278.

RIBEIRO, Simone. Quem faz a educação? Narrativas, conhecimentos e táticas de professoras da escola pública. Curitiba: Appris, 2016a.

RIBEIRO, Marlene. Movimento camponês, trabalho e educação: liberdade, autonomia, emancipação: princípios/fins da formação humana. São Paulo: Expressão Popular, 2010.

. Educação do Campo: condições que inviabilizam o que a legislação garante. In: SOUZA, Dileno Dustan Lucas de; RIBEIRO, Simone. Vozes da subalternidade. Juiz de Fora: Templo gráfica e editora, 2016b. p. 13-34. 


\section{RESUMO}

As lógicas que sustentam a manutenção da vida e os saberes dos povos do campo precisam ocupar espaço nas discussões que repensam o papel e a função social da escola. Pensando nisso, o objetivo deste texto é refletir sobre o lugar do cotidiano e a construção do conhecimento dentro e fora da escola rural, sustentado pelo ideário de Paulo Freire e Michel de Certeau sobre os sujeitos e seus cotidianos. Também nos propomos a analisar práticas avaliativas focadas na alfabetização, empreendidas por escolas rurais nas décadas de 1980/1990, período de grande migração campo/cidade ocorrida em um município de Minas Gerais. Os resultados apontam a necessidade de lançar um novo olhar para a escola que se localiza no campo, seus currículos e práticas avaliativas, seus sujeitos e suas comunidades.

Palavras-chave: Cotidiano. Escolas rurais. Avaliação.

\section{THE PLACE OF QUOTIDIAN IN RURAL SCHOOLS}

\section{ABSTRACT}

The logics that support the maintenance of life and the knowledge of the rural people need to occupy space in the discussions that rethink the role and social function of the school. Thinking about this, the purpose of this text is to reflecton the place of quotidiun and the construction of knowledge inside and outside the rural school, supported by the ideas of Paulo Freire and Michel de Certeau about the subjects and their daily lives. Weal so propose analyzing evaluative practices focused on literacy, undertaken by rural schools in the 1980s and 1990s, a period of great rural / urban migration in a municipality of Minas Gerais. The results point out the need to launch a new look at the school located in the country side, its curricula and evaluative practices, its subjects and their communities.

Keywords: Quotidian. Rural schools. Evaluation.

\section{EL LUGAR DEL COTIDIANO EN LAS ESCUELAS RURALES}

\section{RESUMEN}

Las lógicas que sostienen el mantenimiento de la vida y los saberes de los pueblos del campo necesitan ocupar espacio en las discusiones que repensan el papel y la función social de la escuela. En este sentido, el objetivo de este texto es reflexionar sobre el lugar del cotidiano y la construcción del conocimiento dentro y fuera de la escuela rural, sostenido por el ideario de Paulo Freire y Michel de Certeau sobre los sujetos y sus cotidianos. También nos proponemos analizar prácticas evaluativas enfocadas en la alfabetización, emprendidas por escuelas rurales en las décadas de 1980/1990, período de gran migración campo/ciudad ocurrida en un municipio de Minas Gerais. Los resultados apuntan la necesidad de lanzar una nueva mirada a la escuela que se ubica en el campo, sus currículos y prácticas evaluativas, sus sujetos y sus comunidades.

Palabras clave: Cotidiano. Escuelas rurales. Evaluación. 